\title{
Oestradiol-17 $\beta$ plasma concentrations after intramuscular injection of oestradiol benzoate or oestradiol cypionate in llamas (Lama glama)
}

\author{
María V Cavilla*, Carolina P Bianchi, Marcelo A Aba
}

\begin{abstract}
Background: Llamas (Lama glama) are induced ovulators and the process of ovulation depends on dominant follicular size. In addition, a close relationship between behavioural estrus and ovulation is not registered in llamas. Therefore, the exogenous control of follicular development with hormones aims to predict the optimal time to mate. Oestradiol-17ß $\left(E_{2}\right)$ and its esters are currently used in domestic species, including camelids, in synchronization treatments. But, in llamas, there is no reports regarding the appropriate dosages to be used and most protocols have been designed by extrapolation from those recommended for other ruminants. The aim of the present study was to characterize plasma $E_{2}$ concentrations in intact female llamas following a single intramuscular (i.m.) injection of two oestradiol esters: oestradiol benzoate (EB) and oestradiol cypionate (ECP).

Methods: Twelve non pregnant and non lactating sexually mature llamas were i.m. injected on day 0 with $2.5 \mathrm{mg}$ of EB ( $(E B$ group, $n=6$ ) or ECP (ECP group, $n=6$ ). Blood samples were collected immediately before injection, at 1 , $6,12,24 \mathrm{~h}$ after treatment and then daily until day 14 post injection. Changes in hormone concentrations with time were analyzed in each group by analysis of variance (ANOVA) using a repeated measures (within-SS) design. Plasma $E_{2}$ concentrations and area under the concentration-time curve (AUC) values were compared between groups by ANOVA. In all cases a Least-Significant Difference test (LSD) was used to determine differences between means. Hormonal and AUC data are expressed as mean \pm S.E.M.

Results: Peak plasma $E_{2}$ concentrations were achieved earlier and were higher in EB group than in ECP group. Thereafter, $E_{2}$ returned to physiological concentrations earlier in EB group (day 5) than in ECP group (day 9). Although plasma $E_{2}$ profiles differed over time among groups there were no differences between them on AUC values.

Conclusions: The i.m. injection of a single dose of both oestradiol esters resulted in plasma $E_{2}$ concentrations exceeding physiological values for a variable period. Moreover, the plasma $E_{2}$ profiles observed depended on the derivative of oestradiol administered. This basic information becomes relevant at defining treatment protocols including oestrogens in llamas.
\end{abstract}

\section{Background}

Llamas (Lama glama) are ruminants with physiological peculiarities, particularly regarding their reproductive physiology. Ovarian follicles develop in a wave-like pattern as in other ruminants: cows [1]; ewes [2]; goats [3], but the process of ovulation requires the stimulus of mating and ejaculation [4-8]. Moreover, only growing,

\footnotetext{
* Correspondence: vcavilla@vet.unicen.edu.ar

Área de Endocrinología, Facultad de Ciencias Veterinarias, UNCPBA, Campus Universitario, Paraje Arroyo Seco s/n, Tandil-7000, Buenos Aires, Argentina
}

dominant follicles $\geq 7 \mathrm{~mm}$ in diameter present at the time of mating have the ability to ovulate [9]. In the absence of ovulation, successive waves of follicular growth and regression that generally overlap, proceed $[10,11]$. The oestrogens produced during those waves determine long periods of receptivity ( $\geq 30$ days), interrupted by short stages of male rejection $[4,12]$. Thus, a set of signals indicative of the presence of a mature follicle is not registered in the llama [5,6,11]. Furthermore, the female might accept the male in the absence of a qualified follicle resulting in ovulation failure. Therefore, 
the control of follicular development with exogenous hormones assuring the presence of a healthy mature follicle at a fixed time after treatment would enable the implementation of reproductive technologies leading to an increase in productivity.

Oestrogens are a family of steroid hormones involved in female reproductive processes regulating and sustaining sexual development and reproductive function. Oestradiol-17 $\beta\left(\mathrm{E}_{2}\right)$ is the most abundant and active of the endogenous oestrogens produced by the ovary [13]. In addition, oestradiol esters are a group of synthetic oestrogens that includes: oestradiol benzoate (EB), oestradiol valerate $(E V)$ and oestradiol cypionate (ECP). Oestradiol$17 \beta$ and EB are commonly used to induce follicular regression and to synchronize wave emergence and ovulation in progestin-treated cattle [14-17]. The inclusion of ECP in hormonal regimens has increased in recent years as in some countries is the only ester available and licensed for use in cattle, but its success to hasten wave emergence has been relatively variable to date $[18,19]$. The time to wave emergence after $\mathrm{E}_{2}$ treatment in cattle, appears to depend on the dose and formulation administered. It appears that the greater the circulating concentrations of $E_{2}$, or the time to return to physiological range, the greater are follicular and FSH suppression $[16,20-22]$. Thus the use of an "optimal" dose or formulation of $E_{2}$ in hormonal regimens is emphasized by the previous observations. Conversely, in camelids information regarding the effects of oestrogens on follicular activity is scanty and controversial [23-26]. In addition, there is no reports regarding the appropriate dosages to be used in llamas and most protocols have been designed by extrapolation from those recommended for other ruminants. While establishing those dose regimens, it has never been considered that camelids show pharmacological differences for the metabolism of several drugs as compared to other ruminants [27-30].

The study hereby reported, was designed to provide a comparative characterization of plasma $E_{2}$ concentrations following a single i.m. injection of two oestradiol esters (EB and ECP). This information would provide basic knowledge useful for a more rational use of these drugs in the species.

\section{Methods}

\section{Animals and treatments}

The experimental design and animal care were performed in compliance with regulations set by the Animal Welfare Committee at the Faculty of Veterinary Sciences, UNCPBA, Tandil, Argentina $\left(37^{\circ} \mathrm{S}, 60^{\circ} \mathrm{W}\right)$ where activities were carried out. Animals were kept isolated from males and fed pasture hay and had free access to water during the entire experimental period. Twelve sexually mature, non pregnant and non lactating female llamas $(107.5 \pm 17.68 \mathrm{Kg})$ were randomly divided into two treatment groups: EB $(n=6)$ and ECP $(n=6)$. On day 0 all animals received a single i.m. injection $(0$ h) of $2.5 \mathrm{mg}$ of oestradiol benzoate (EB, Benzoato de Estradiol Syntex ${ }^{\oplus}$, Syntex SA, Buenos Aires, Argentina) or oestradiol cypionate (ECP, ecp estradiol ${ }^{\ominus}$, König, Buenos Aires, Argentina) into the hind leg in the region of the semitendinosus muscle. The dose of EB was selected based on previous studies in llamas and alpacas [24,31]. In general, a larger dose of EB has been used in camelids as compared to that used in synchronization programs in cattle $[15,24,26,31]$, probably in relation to a higher metabolic rate reported in camelids for different drugs [27-30]. In addition, to allow a direct comparison between esters and due to the lack of reports using ECP in the specie the same dose was used for ECP.

\section{Blood sampling}

Blood samples were collected into heparinized tubes immediately before injection, at 1, 6, 12, $24 \mathrm{~h}$ after treatment, and then daily until day 14 post injection. In order to minimize damage to the jugular veins due to the high frequency sampling protocol, venipuncture was performed alternately at high, medium and low positions on the left and right sides of the neck as previously described by Aba et al. [32]. Plasma samples were separated by centrifugation and stored at $-20^{\circ} \mathrm{C}$ until analyzed.

\section{Hormone determinations}

Oestradiol-17 $\beta$ plasma concentrations were measured using an RIA Kit (Siemens Medical Solutions Diagnostics, Los Angeles, CA, USA) reported for use with bovine plasma [33], and validated for use with llama plasma after minor modifications [6]. Plasma and standards were previously extracted using diethyl ether (Merck, Buenos Aires, Argentina). The intra-assay coefficient of variation was below $10 \%$ for concentrations between 5.6 and $180 \mathrm{pmol} \mathrm{l}^{-1}$. The inter-assay coefficient of variation, calculated from the precision profiles of five standard curves, was below $6 \%$ for concentrations between 5.6 and $180 \mathrm{pmol} \mathrm{l}^{-1}$. The lowest amount of $\mathrm{E}_{2}$ detectable was $5.6 \mathrm{pmol} \mathrm{l}^{-1}$. Plasma progesterone $\left(\mathrm{P}_{4}\right)$ concentrations were measured using an RIA Kit (Siemens Medical Solutions Diagnostics, Los Angeles, CA, USA) previously validated for use with llama plasma [34]. The sensitivity of the assay was $0.3 \mathrm{nmol} \mathrm{l}^{-1}$ and the intra-assay coefficient of variation was below $13 \%$ for concentrations between 0.4 and $128 \mathrm{nmol} \mathrm{l}^{-1}$. All samples were measured in duplicates. Hormone concentrations are expressed in SI units. To convert from pmol $\mathrm{l}^{-1}$ to $\mathrm{pg} \mathrm{ml} \mathrm{m}^{-1}$ and from nmol $\mathrm{l}^{-1}$ to $\mathrm{ng} \mathrm{ml}^{-1}$, a factor of 3.7 for oestradiol- $17 \beta$ and 3.2 for progesterone should be used. 


\section{Analysis of data}

In order to establish a physiological plasma $\mathrm{E}_{2}$ concentration upper limit before treatment, twice the standard deviation (SD) was added to the general mean as previously described by Vynckier et al. [35]. Any concentration above $(\mathrm{P}<0.05)$ this limit was considered pharmacological. Changes in hormone concentrations with time on each treatment group were analyzed by analysis of variance (ANOVA) using a repeated measures (within-SS) design. Mean $\mathrm{E}_{2}$ concentrations at each time were statistically compared among groups by ANOVA. In all cases, a Fisher's Least-Significant Difference test (LSD) was used to determine differences between means. Log-transformation was used for plasma $\mathrm{E}_{2}$ concentrations before analyses to stabilize variances. The area under the concentration-time curve (AUC) from time zero to the last measurable concentration was calculated by the trapezoidal rule [36]. The AUC values obtained after the injection of both esters was statistically compared between groups by ANOVA. Statistical analyses were carried out using the Statistica/W, release 4.0 software package (Statsoft Inc., Tulsa, OK, USA, 1993). Statistical significance was set at $P<0.05$. Hormonal and AUC data are expressed as mean \pm S.E.M unless otherwise specified.

\section{Results}

\section{Physiological plasma $E_{2}$ concentrations}

Oestradiol-17 $\beta$ plasma concentrations varied widely between animals at the beginning of the study (ranging from 13.7 to $44.7 \mathrm{pmol} \mathrm{l}^{-1}$ ). Mean plasma $\mathrm{E}_{2}$ concentration before injection (considering all females) was $33.1 \pm$ 11.7 pmol l$^{-1}$ (mean \pm SD). The physiological upper limit for plasma $E_{2}$ concentrations was established at $56.5 \mathrm{pmol}^{1}$.

\section{Plasma $E_{2}$ concentrations and AUC values after oestradiol esters injection}

The administration of both formulations resulted in plasma $\mathrm{E}_{2}$ concentrations largely exceeding physiological values. Mean plasma $E_{2}$ concentrations during 14 days after i.m. injection of EB and ECP are shown in Figure 1. In $\mathrm{EB}$ group, $\mathrm{E}_{2}$ plasma concentrations increased sharply $(\mathrm{P}<0.0001)$ by $1 \mathrm{~h}$ after injection, reaching peak concentrations $\left(484.9 \pm 85.6 \mathrm{pmol} \mathrm{l}^{-1}\right)$ by $6 \mathrm{~h}$ after injection. Oestradiol-17 $\beta$ plasma concentrations remained elevated until $12 \mathrm{~h}$ and then followed a biphasic decline. Firstly, $\mathrm{E}_{2}$ concentrations underwent a sharp decrease between $12 \mathrm{~h}$ and day 1 , remained relatively stable between days 1 and 2 and steadily decreased onwards returning to physiological values by day 5 post injection. In ECP group, $\mathrm{E}_{2}$ concentrations increased slowly from $6 \mathrm{~h}$ after injection $(\mathrm{P}<0.0001)$ until peak concentrations $\left(157.1 \pm 8.7 \mathrm{pmol} \mathrm{l}^{-1}\right)$ were reached on day 1. Thereafter, plasma $\mathrm{E}_{2}$ concentrations declined slowly, until concentrations no longer distinguishable from physiological were attained on day 9. Subsequently, plasma $\mathrm{E}_{2}$ concentrations fluctuated close to physiological values until the end of the study.

Although plasma $\mathrm{E}_{2}$ concentrations profiles differ according to treatment, the AUC values obtained following injection were similar between groups (EB: 1336.01 $\pm 157.4 \mathrm{pmol}^{*}$ day/l; ECP: $1189.78 \pm 87.44 \mathrm{pmol}$ *day/l; P $=0.5306)$. Thus, mean $\mathrm{E}_{2}$ concentrations in EB group were higher than in ECP group at all times beyond the 0 h sample until day 2 with a rapid fell onwards. In contrast, in ECP group mean $\mathrm{E}_{2}$ concentrations experienced a slower increase, but more prolonged in time, attaining values higher than in EB group between day 6 and day 13 inclusive. On days 3 to 5 and on day 14 plasma $E_{2}$ concentrations were similar among groups. Plasma $\mathrm{P}_{4}$ concentrations remained bellow $3 \mathrm{nmol} \mathrm{l}^{-1}$ in all females during the entire period of study.

\section{Discussion}

Plasma $E_{2}$ concentrations and its variability between animals recorded before treatment in the present study (range from 13.7 to $44.7 \mathrm{pmol} \mathrm{l}^{-1}$ ) are consistent with previous reports in llamas $[6,37,38]$. This observation indicates animals were at different stages of follicular development at the time of treatment, as it has been established a close relationship between follicular activity and $E_{2}$ secretion in llamas $[5,6,38,39]$. In addition, the plasma $E_{2}$ concentration established as the physiological upper limit in the present study was somehow in agreement to that previously registered during the follicular phase (17 to $47 \mathrm{pmol} \mathrm{l}^{-1}$ ) in llamas [38]. The fact that plasma $\mathrm{P}_{4}$ concentrations remained bellow $3 \mathrm{nmol}$ $\mathrm{I}^{-1}$ in all cases indicates that no ovulations occurred during the study [6].

To our knowledge, this is the first report showing the plasma $E_{2}$ profile following a single i.m. injection of ECP and its comparison to the profile obtained after injection of EB in llamas. Treatment with both oestradiol derivatives induced plasma $E_{2}$ concentrations exceeding those considered physiological for the species. Moreover, the plasma $\mathrm{E}_{2}$ profiles recorded in the present study clearly depended on the ester administered and were consistent with that registered in cows by Vynckier et al. [35]. Plasma $\mathrm{E}_{2}$ concentrations increased rapidly and peaked earlier in EB group with values three-times higher than in ECP group. Similar results were previously observed after EB injection in bovines [21,22].

Peak plasma $E_{2}$ concentrations achieved after EB injection in the present study were higher than those recorded before in camelids [24,31] and were attained earlier than observed by others [24] in alpacas. Although there is no clear explanation for the divergences 


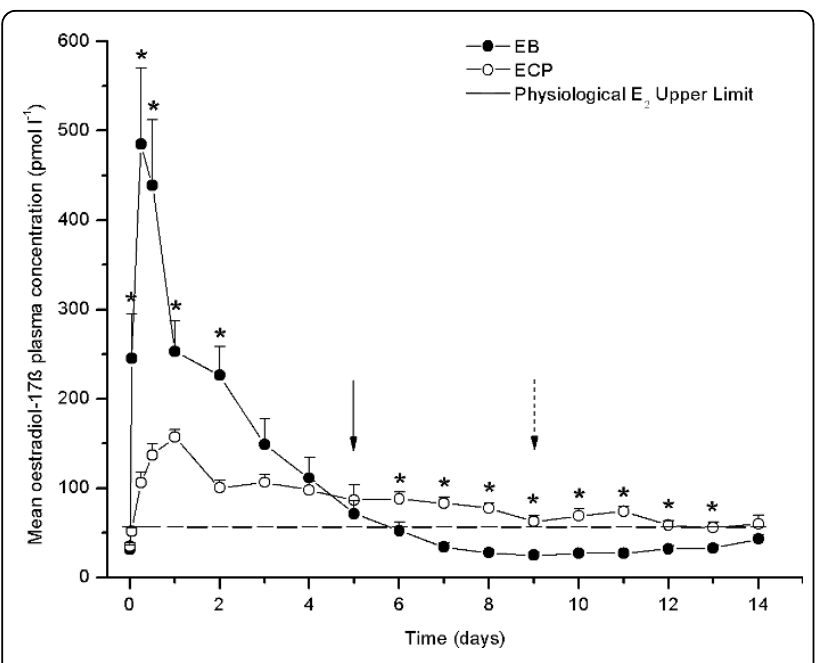

Figure 1 Mean plasma oestradiol $17-\beta$ concentration in llamas injected intramuscularly with oestradiol benzoate or oestradiol cypionate. Mean plasma oestradiol 17- $\beta\left(E_{2}\right)$ concentration immediately before injection $(0 \mathrm{~h})$, at $1,6,12,24 \mathrm{~h}$ post injection, and then daily until day 14 after a single intramuscular injection of $2.5 \mathrm{mg}$ of oestradiol benzoate (EB group; closed circle) or oestradiol cypionate (ECP group; open circle) in llamas ( $n=6 /$ group). The broken line indicates the physiological plasma $E_{2}$ concentrations upper limit established. ${ }^{(*)}$ Mean values differ between groups at $\mathrm{P}<$ 0.05. Within treatments groups, a solid (EB group) or dashed (ECP group) arrow indicates the day on which plasma $E_{2}$ concentrations returned to physiological values $(P>0.05)$.

registered between studies, it could be speculated that differences in blood sampling schedule, sensitivity of hormone assays and formulation of hormonal products, may be responsible for the discrepancy.

Once peak plasma $\mathrm{E}_{2}$ concentrations were reached, the declination rate also differed between esters. The biphasic decline of plasma $\mathrm{E}_{2}$ concentrations until physiological values on day 5 in EB group is in agreement with previous reports in alpacas and cows [24,35]. As stated by Vynckier et al. [35] these biphasic decline suggest an initial phase of distribution followed by an elimination phase. In contrast, in ECP group, the decreasing phase of the curve was shorter and plasma $E_{2}$ concentrations fluctuated close to physiological values from day 9 onwards. Although the pattern of decline observed for ECP in our study is consistent with that recorded in cows by Vynckier et al. [35], they showed that concentrations returned to physiological values slightly earlier (day 7) in this species. The slower return to physiological values in ECP compared to EB group indicates a longer half-life for ECP as has been registered previously in cattle $[17,19,35]$.

From the analysis of plasma $\mathrm{E}_{2}$ concentrations, it is apparent that ECP was absorbed at a lower rate than $\mathrm{EB}$, but persisted elevated in plasma for a longer period (8 and 4 days, respectively). Besides the different rates of absorption, the same amount of drug was released from the injection site for both esters, since by the end of the study the AUCs values were similar between groups. These findings are consistent with the fact that the esterification process prolongs the half-life of $\mathrm{E}_{2}$. Apparently, the ester injected influences the mode that $E_{2}$ is released from the injection site. Thus, there is an inverse relationship between the extension of the ester chain and its water solubility and consequently, on its absorption rate. Once in circulation, the esters are hydrolyzed to $E_{2}$, the active hormone. Consequently, the duration of action appears to depend on the rate of absorption more than the metabolism [40].

It has been suggested in llamas that hormonal treatments with progestogens are effective in completely prevent follicular development for a period of up to 7 days with the lowest follicular activity registered between days 5 and 7 after beginning of treatment [32-38]. Thereafter, most attempts to control follicular activity includes short protocols (5 to 7 days) and a combination of a progestogen and oestrogens. According to the results hereby presented, $E_{2}$ plasma concentrations would remain at pharmacological concentrations beyond the day of progestogen withdrawal after ECP treatment. Conversely, plasma $\mathrm{E}_{2}$ concentrations would have return to physiological values before the end of the synchronization protocol after EB injection. Whether this might influence the outcome of the synchronization treatment or not remains to be elucidated.

\section{Conclusions}

To our knowledge, this is the first study that provides a characterization of the plasma $\mathrm{E}_{2}$ concentrations profile following a single i.m. injection of ECP and a direct comparison to that obtained after EB injection in intact female llamas. Both esters effectively induced pharmaco$\operatorname{logical} \mathrm{E}_{2}$ concentrations, however, plasma $\mathrm{E}_{2}$ profiles depended on the formulation administered. Peak plasma $\mathrm{E}_{2}$ concentrations were higher and were attained earlier after EB injection compared to ECP with an earlier return to physiological values. This basic information becomes relevant at defining treatment protocols including oestrogens in llamas.

\section{Acknowledgements}

This study was supported by grants from Agencia Nacional de Promoción Científica y Tecnológica (PICT 08-14231). MVC and CPB are holders of a fellowship from Consejo Nacional de Investigaciones Científicas y Técnicas (CONICET).

\section{Authors' contributions}

MVC participated in developing the design of the experiment, carried out the experiment, gathered and analyzed the data, and drafted the manuscript. CPB contributed in carrying out the experiment and with contents of the manuscript. MAA as the director of the doctoral project of MVC designed the experiment, contributed in carrying out the experiment, 
with the analysis of the data and revising critically the contents of the manuscript. All authors have read and approved the final manuscript.

\section{Competing interests}

The authors declare that they have no competing interests.

Received: 15 December 2009

Accepted: 11 February 2010 Published: 11 February 2010

\section{References}

1. Ginther OJ, Kastelic JP, Knoft L: Composition and characteristics of follicular waves during the bovine estrus cycle. Anim Reprod Sci 1989, 20:187-200.

2. Evans AC, Duffy P, Hynes N, Boland MP: Waves of follicle development during the estrous cycle in sheep. Theriogenology 2000, 53:699-715.

3. Rubianes $E$, Menchaca $A$ : The pattern and manipulation of ovarian follicular growth in goats. Anim Reprod Sci 2000, 78:271-287, (review)

4. San-Martín M, Copaira M, Zuniga J, Rodreguez R, Bustinza G, Acosta L: Aspects of reproduction in the alpaca. J Reprod Fertil 1968, 16:395-399.

5. Bravo PW, Fowler ME, Stabenfeldt GH, Lasley BL: Ovarian follicular dynamics in the llama. Biol Reprod 1990, 43:579-585.

6. Aba MA, Forsberg M, Kindahl H, Sumar J, Edqvist LE: Endocrine changes after mating in pregnant and non-pregnant llamas and alpacas. Acta Vet Scand 1995, 36:489-498.

7. Chen BX, Yuen ZX, Pan GW: Semen-induced ovulation in the Bactrian camel (Camelus bactrianus). J Reprod Fertil 1985, 74:335-339.

8. Adams GP, Ratto MH, Huanca W, Singh J: Ovulation-Inducing Factor in the Seminal Plasma of Alpacas and Llamas. Biol Reprod 2005, 73:452-457.

9. Bravo PW, Stabenfeldt GH, Lasley BL, Fowler ME: The effect of ovarian follicle size on pituitary and ovarian responses to copulation in domesticated South American camelids. Biol Reprod 1991, 45:553-559.

10. Adams GP, Sumar J, Ginther OJ: Effects of lactational and reproductive status on ovarian follicular waves in llamas (Lama glama). J Reprod Fertil 1990, 90:535-545.

11. Vaughan JL, Tibary A: Reproduction in female South American camelids: A review and clinical observations. Small Rumin Res 2006, 61:259-281.

12. England BG, Foote WC, Cardozo AG, Matthews DH, Riera S: Oestrus and mating behaviour in the llama (Lama glama). Anim Behav 1971, 19:722-726.

13. Reeves JJ: Endocrinology of Reproduction. Reproduction in farm animals Philadelphia: Lea \& FebigerHafez ESE , Fifth 1987, 85-106.

14. Bo GA, Adams GP, Pierson RA, Tribulo HE, Caccia M, Mapletoft RJ: Follicular wave dynamics after estradiol-17 $\beta$ treatment of heifers with or without a progestogen implant. Theriogenology 1994, 41:1555-1569.

15. Bo GA, Baruselli PS, Moreno D, Cutaia L, Caccia M, Tríbulo R, Tríbulo HE, Mapletoft RJ: The control of follicular wave development for selfappointed embryo transfer programs in cattle. Theriogenology 2002, 57:53-72, (review).

16. Burke CR, Mussard ML, Gasser CL, Grum DE, Day ML: Estradiol benzoate delays new follicular wave emergence in a dose-dependent manner after ablation of the dominant ovarian follicle in cattle. Theriogenology 2003, 60:647-658.

17. Martínez MF, Kastelic JP, Bo GA, Caccia M, Mapletoft RJ: Effects of oestradiol and some of its esters on gonadotrophin release and ovarian follicular dynamics in CIDR-treated beef cattle. Anim Reprod Sci 2005 , 86:37-52.

18. Thundathil J, Kastelic JP, Mapletoft RJ: The effect of estradiol cypionate (ECP) on ovarian follicular development and ovulation in dairy cattle. Can J Vet Res 1997, 61:314-316.

19. Colazo MG, Kastelic JP, Mapletoft RJ: Effects of estradiol cypionate (ECP) on ovarian follicular dynamics, synchrony of ovulation, and fertility in CIDR-based, fixed-time Al programs in beef heifers. Theriogenology 2003 60:855-865.

20. Bo GA, Bergfelt DR, Brogliatti GM, Pierson RA, Adams GP, Mapletoft RJ: Local versus systemic effects of exogenous estradiol-17 $\beta$ on ovarian follicular dynamics in heifers with progestogen implants. Anim Reprod Sci 2000, 59:141-157.

21. O'Rourke M, Diskin MG, Sreenan JM, Roche JF: The effect of dose and route of oestradiol benzoate administration on plasma concentrations of oestradiol and FSH in long-term ovariectomised heifers. Anim Reprod Sci 2000, 59:1-12.
22. Diskin MG, Austin EJ, Roche JF: Exogenous hormonal manipulation of ovarian activity in cattle. Domest Anim Endocrinol 2002, 23:211-228, (review).

23. D'Occhio MJ, Novoa C, Vera WG, Davalos : Ovarian follicle regression and emergence of new follicular wave after injection of $17 \beta$-oestradiol in alpacas. Australian Society for Reproductive Biology 1997, 29:102.

24. Vaughan JL: Control of ovarian follicular growth in the alpaca (Lama pacos). PhD thesis Central Queensland University 2001.

25. Ratto $M H$, Singh J, Huanca W, Adams GP: Ovarian follicular wave synchronization and pregnancy rate after fixed-time natural mating in llamas. Theriogenology 2003, 60:1645-1656.

26. Skidmore JA, Adams GP, Billah M: Synchronisation of ovarian follicular waves in the dromedary camel (Camelus dromedarius). Anim Reprod Sci 2009, 114:249-255.

27. Oukessou M: Kinetic disposition of flunixin meglumine in the camel (Camelus dromedarius). Vet Res 1994, 25:71-75.

28. Ali BH, Oukessou M, Bashir AK: Pharmacokinetics considerations in the camel (Camelus dromedarius). Comp Biochem Physiol 1996, 115:1-9.

29. Navarre CB, Ravis WR, Nagilla R, Deshmukh D, Simpkins A, Duran SH, Pugh DG: Pharmacokinetics of flunixin meglumine in llamas following a single intravenous dose. J Vet Pharmacol Ther 2001, 24:361-364.

30. Navarre CB, Ravis WR, Nagilla R, Simpkins A, Duran SH, Pugh DG: Pharmacokinetics of phenylbutazone in llamas following single intravenous and oral doses. J Vet Pharmacol Ther 2001, 24:227-231.

31. Cancino AK: Control exógeno de la dinámica folicular ovárica y respuesta superovulatoria en llamas (Lama glama) con y sin cría al pie. (Exogenous control of follicular dynamics and superovulatory response in lactating and non lactating llamas (Lama glama). Master of Science thesis Facultad de Cs. Agrarias, Universidad Nacional de Mar del Plata. Balcarce, Argentina 2005, 106.

32. Aba MA, Quiroga MA, Auza N, Forsberg M, Kindahl H: Control of ovarian activity in llamas (Lama glama) with medroxyprogesterone acetate. Reprod Domest Anim 1999, 34:471-476.

33. Sirois J, Fortune JE: Lengthening the bovine estrous cycle with low levels of exogenous progesterone: a model for studying ovarian follicular dominance. Endocrinology 1990, 127:916-925.

34. Bianchi CP, Meikle A, Sartore I, González F, Aba MA: Uterine estrogen receptor alpha and progesterone receptor during the follicular and luteal phase in llamas. Anim Reprod Sci 2007, 99:117-126.

35. Vynckier L, Debackere M, De Kruif A, Coryn M: Plasma estradiol-17ß concentrations in the cow during induced estrus and after injection of estradiol-17 $\beta$ benzoate and estradiol-17 $\beta$ cypionate-a preliminary study. J Vet Pharmacol Ther 1990, 13:36-42.

36. Baggot J: Pharmacokinetics: disposition and fate of drugs in the body. Veterinary Pharmacology and Therapeutics Ames lowa 50014, USA: Iowa State University PressAdams R 1995, 18-52.

37. Aba MA: Hormonal interrelationships in reproduction of female llamas and alpacas. PhD thesis Swedish University of Agricultural Sciences, Acta Univ. Agricult. Sueciae Vet 1998, 35.

38. Chaves MG, Aba M, Agüero A, Egey J, Berestin V, Rutter B: Ovarian follicular wave pattern and the effect of exogenous progesterone on follicular activity in non-mated llamas. Anim Reprod Sci 2002, 69:37-46.

39. Aba MA: Studies on the reproductive endocrinology of llamas and alpacas from mating throughout early pregnancy. Master of Science thesis Swedish University of Agricultural Sciences, Uppsala 1995, 11-78.

40. Mapletoft RJ, Colazo MG, Martínez MF, Kastelic JP: Ésteres de estrógeno para la sincronización de la emergencia de la onda folicular y la ovulación en animales tratados con dispositivos con progesterona. (Estradiol esters for synchronization of follicular wave emergence and ovulation in animals treated with progesterone releasing intravaginal devices). Proceedings of the $V$ International Symposium of Animal Reproduction, IRAC: 27-29 June Córdoba, Argentina 2003, 55-67.

doi:10.1186/1751-0147-52-13

Cite this article as: Cavilla et al:: Oestradiol- $17 \beta$ plasma concentrations after intramuscular injection of oestradiol benzoate or oestradiol cypionate in Ilamas (Lama glama). Acta Veterinaria Scandinavica 2010 52:13. 